\title{
A cross-sectional evaluation of adiponectin plasma levels in patients with schizophrenia and schizoaffective disorder
}

Linda Hanssens ${ }^{\mathrm{a}}$, Ruud van Winkel ${ }^{\mathrm{b}, \mathrm{c}}$, Martien Wampers ${ }^{\mathrm{b}}$, Dominique Van Eyck ${ }^{\mathrm{b}}$, Andre Scheen ${ }^{\mathrm{d}}$, Jean-Yves Reginster $^{\mathrm{a}}$, Julien Collette ${ }^{\mathrm{e}}$, Joseph Peuskens ${ }^{\mathrm{b}}$, Marc De Hert ${ }^{\mathrm{b}}$

${ }^{a}$ Department of Epidemiology and Public Health, University Liège, Belgium

${ }^{b}$ University Psychiatric Center Catholic University Leuven, Leuvensesteenweg 517, 3070 Kortenberg, Belgium

${ }^{c}$ Department of Psychiatry and Neuropsychology, EURON, South Limburg Mental Health Research and Teaching Network, Maastricht University; PO box 616, 6200 MD Maastricht, The Netherlands

${ }^{d}$ Department of Diabetology, CHU de Sart Tilman, University Liège, Belgium

${ }^{\mathrm{e}}$ Department of Clinical Biology, CHU de Sart Tilman, University Liège, Belgium

\begin{abstract}
:
Background: In recent years, several studies showed increased rates of hyperglycaemia, diabetes, dyslipidemia, metabolic syndrome as well as cardiovascular disease in schizophrenic patients. The underlying mechanism, however, is poorly understood. Adiponectin is a recently identified adipocyte-derived protein, with low adiponectin levels being associated with metabolic abnormalities such as obesity, insulin resistance and type 2 diabetes. Methods: Fasting adiponectin levels were assessed in a cross-sectional sample of 386 patients with schizophrenia or schizoaffective disorder. All patients were on monotherapy of second-generation antipsychotics (SGA) and underwent an extensive metabolic screening including an oral glucose tolerance test (OGTT). Results: Adiponectin plasma levels were inversely correlated with BMI, and differed significantly between patients with normal weight, overweight or obesity $(p<0.05)$. Patients who met criteria for the metabolic syndrome, according to adapted National Cholesterol Educational Program - Adult Treatment Panel criteria (NCEP-ATP III) (29.3\%), had significantly lower adiponectin levels than patients not meeting metabolic syndrome criteria $(p<0.0001)$. Patients without glucose abnormalities $(78 \%)$ had significantly higher adiponectin levels than patients with diabetes $(5.7 \%)(p<0.05)$. After controlling for components of metabolic syndrome and sex, antipsychotic medication independently influenced adiponectin levels $(p<0.0001)$, with the lowest mean levels in patients on clozapine and olanzapine. Conclusions: Adiponectin levels in schizophrenic patients mirror what is observed in the general population, with the lowest levels in the most metabolically comprised subjects. However, antipsychotic medication may also influence adiponectin regulation independently, a finding that should be confirmed in longitudinal studies.
\end{abstract}

Keywords: Schizophrenia; Metabolic syndrome; Antipsychotic; Adiponectin; Diabetes

\section{Introduction}

Over the last years, convincing evidence has been put forward to suggest an increased prevalence of metabolic abnormalities such as diabetes and the metabolic syndrome in patients with schizophrenia (Allison et al., 1999; Homel et al., 2002; Scheen and De Hert, 2005, 2007). An emerging literature suggests an association of certain antipsychotics with the development of metabolic abnormalities (Allison and Casey, 2001 ; Jin et al., 2004; Dufresne, 2007; Meyer and Koro, 2004; Newcomer, 2005, 2007a,b). These metabolic abnormalities may in turn contribute to the higher risk of cardiovascular disease in patients with schizophrenia (Casey, 2005; De Nayer et al., 2005; Haupt and Newcomer, 2001; Hennekens et al., 2005; Jin et al., 2002, 2004; Newcomer, 2005; Newcomer, 2007a; Scheen and De Hert, 2005, 2007; Tschoner et al., 2007). However, the mechanism underlying antipsychotic-induced metabolic dysregulation is still unclear. Several hypotheses have been suggested, such as appetite stimulation which is linked to the affinity of some SGAs to neurotransmitters involved in food intake, 5HT2a and 2c serotoninergic receptors, but also H1 histaminergic, alphal and alpha2 adrenergic receptors and muscarinic (M3) receptors (Elman et al., 1999, 2002; Elmquist and Flier, 2004; Kroeze et al., 2003; Newcomer, 2005; Reynolds et al., 2002). In order to understand the underlying mechanisms, Bergman and Ader (2005) and Ader et al. (2005) evaluated the effects on antipsychotics on glucose homeostasis in dogs and found that the hyperinsulinemic compensation was inadequate to counter insulin resistance under olanzapine treatment, although it is unclear whether this was due to a central or peripheral effect. 
Changes in insulin sensitivity, potentially induced by deregulated adipocytes are of particular interest with regard to the metabolically deleterious effects of antipsychotic medications. Over the last decade, it became apparent that these cells play an important endocrine role in ensuring normal metabolic homeostasis. They secrete a variety of proteins like resistin, 1L-6, TNF alpha, and adiponectin, which affect insulin sensitive organs like the liver and muscles (Sato et al., 2001). Free Fatty Acids (FFA) produced by adipocytes, essentially in presence of abdominal obesity, can induce insulin resistance (Arner, 2001).

In human plasma, circulating adiponectin levels are high $(5-30 \mu \mathrm{g} / \mathrm{ml})$ (Hotta et al., 2000). The protein, also known as adipocyte complement related protein, plays a role in glucose and lipid homeostasis (Hara et al., 2005; Lihn et al., 2005; Guerre-Millo, 2008; Sherer et al., 1995). It decreases the postprandial rise of plasma FFAs and improves post-absorptive insulin suppression of glucose production by the liver. A strong correlation between adiponectin levels and insulin sensitivity has been established (Arita et al., 1999; Berg et al., 2001, 2002; Lihn et al., 2005; Guerre-Millo, 2008). Plasma adiponectin levels are lower in obese than in lean people (Arita et al., 1999; Matsuzawa et al., 2004). The protein is also associated with anti-atherogenic properties, preventing the development of atherosclerotic plaque, by inhibiting TNF alpha production by macrophages (Berg et al., 2002; Matsuzawa et al., 2005a,b). Decreased levels of adiponectin are associated with insulin resistance and hyperinsulinemia (Weyer et al., 2001; Yamauchi et al., 2001). High levels of adiponectin are associated with low risk of developing type 2 diabetes. In non-diabetic patients adiponectin levels are negatively correlated with triglycerides and low levels of adiponectin may accelerate atherosclerosis in patients with dyslipidemia (Matsuda et al., 2002; Matsubara et al., 2002). A recent population based study carried out by Dekker et al., 2008, showed that high levels of adiponectin did predict mortality, in particular in patients with prevalent CVD. The authors hypothesized that adiponectin would protect against metabolic and vascular diseases, but in the study, patients already suffering from CVD, adiponectin was compensatory up-regulated. The metabolic effects of adiponectin are mediated through the activation of 5'Adenosine-Mono-Phosphate-activated-kinase (AMPK). This enzyme also mediates the vascular endothelial cells and the effects on the myocardial muscle through different processes which lead to its protective effects against cardiovascular diseases. Distinct adiponectin receptors, AdipoRl and AdipoR2 which are unequally distributed in the target tissues, are involved.

In patients with schizophrenia, adiponectin levels were found to correlate with metabolic parameters in clozapine-treated patients in a similar fashion as found in the general population (Bai et al., 2007). However, higher levels of insulin-resistance were found in clozapine-treated patients compared to subjects from the general population matched for BMI and waist, indicating that illness-related or treatment-related factors may further increase insulin resistance in overweight patients with schizophrenia (Wu et al., 2007). A recent study in patients with schizophrenia that focused on the early changes in glucose metabolism after initiation of an atypical antipsychotic suggested that glucose dysregulation may develop as early as within three months after initiation (van Winkel et al., 2008). These dysregulations may involve adipocyte hormones such as adiponectin, as was suggested by a recent study by Bai and colleagues who found that independent of age and BMI, serum adiponectin was a biomarker for the metabolic syndrome in clozapine-treated patients with schizophrenia (Bai et al., 2007). The current study aimed to i) assess plasma adiponectin levels in 386 patients with schizophrenia as a function of metabolic outcomes and ii) assess differential effects of antipsychotic medication on adiponectin levels, controlling for the potentially confounding effects of the individual components of the metabolic syndrome and sex. These confounders were based on previous research in non-psychiatrically ill populations.

\section{Methods}

In November 2003, a naturalistic screening and monitoring protocol for metabolic abnormalities was initiated and is still ongoing at the university psychiatric hospital and affiliate services of the University Psychiatric Centre Catholic University Leuven. The screening methods have been described in detail elsewhere (De Hert et al., 2006a,b; Van Winkel et al., 2006). In short, referral by the treating psychiatrist for metabolic screening and monitoring is a clinical routine in the hospital and its affiliate services. Antipsychotic drug regimens are recorded and patients are being monitored using fasting laboratory tests, Oral Glucose Tolerance Tests (OGTT) and clinical examinations. Psychiatric diagnoses according to DSM-IV criteria were established by experienced psychiatrists affiliated with the University Centre and responsible for the patient's treatment. Written informed consent was obtained from all patients. The study was approved by the local ethical committee and conducted in accordance with the Declaration of Helsinki and Good Clinical Practice requirements. Patients who were on monotherapy of SGA for at least 6 months were considered for this study. 386 patients, among the assessed patient cohort, with a diagnosis of schizophrenia or schizoaffective disorder, fulfilled this criterion. 
All patients had a 75gr glucose load Oral Glucose Tolerance Test (OGTT) and a fasting blood sample taken for the assessment of individual items among the assessed patient cohort of the metabolic syndrome. Blood pressure and waist were assessed during a clinical examination. Patients were initiated on an overnight fast and were monitored during the OGTT.

Plasma samples were centrifuged at $4{ }^{\circ} \mathrm{C}$ and frozen at $-80{ }^{\circ} \mathrm{C}$. Adiponectin samples were assessed by a solid phase ELISA which contains NSO-expressed recombinant human adiponectin and has shown to accurately quantitate the recombinant factor (B-Bridge International, 2002). The assay employs the quantitative sandwich enzyme immunoassay technique.

The presence of the metabolic syndrome was assessed using the adapted National Cholesterol Educational Program -Adult Treatment Panel (NCEP-ATP III) criteria (fasting glucose $\geq 100 \mathrm{mg} / \mathrm{dl}$ plus the inclusion of treatment for hypertension, with lipid lowering medication and/or with antidiabetic medication as criteria) (NCEP, 2001 ; Grundy et al., 2004). For the diagnosis of diabetes and pre-diabetic abnormalities the criteria of the American Diabetes Association were used (Impaired fasting glucose (IFG) $\geq 100 \mathrm{mg} / \mathrm{dl}$ and $<125 \mathrm{mg} / \mathrm{dl}$, Impaired Glucose Tolerance (IGT) glucose $\geq 140 \mathrm{mg} / \mathrm{dl}$ and $<200 \mathrm{mg} / \mathrm{dl}$ at $2 \mathrm{~h}$ in the OGTT) (Expert Committee, 2003, 2008)). Markers of $\beta$-cell function (HOMA $\beta$ cell) and insulin resistance (HOMA IR) were calculated using the homeostasis model assessment (HOMA) index algorithm derived from the fasting glucose and insulin concentrations (Matthews et al., 1985).

Descriptive statistics were computed for the basic demographic and clinical variables as well as for the laboratory variables relevant for the evaluation of metabolic abnormalities.

The association between adiponectin level and the individual components of the metabolic syndrome was measured by a Pearson correlation. Independent t-tests were used to evaluate differences in mean adiponectin levels as a function of presence/absence of the metabolic syndrome, gender, elevated triglyceride levels $(\geq 150$ $\mathrm{mg} / \mathrm{dl}$ ), and low HDL cholesterol levels (male $<40 \mathrm{mg} / \mathrm{dl}$, female $<50 \mathrm{mg} / \mathrm{dl}$ ). Chi-square tests were used to test the association between antipsychotic treatment and the presence/absence of the metabolic syndrome and the presence/absence of glucose abnormalities.

The effect of BM1 category (normal weight, overweight, obese), glucose (diabetes, prediabetes, no abnormalities) and lipid abnormalities on mean adiponectin levels was tested by means of a one-way ANOVA as was the influence of antipsychotic treatment on mean glucose, insulin and adiponectin levels.

An ANCOVA was used to test the effect of antipsychotic treatment on mean adiponectin level when controlling for the individual components of the metabolic syndrome as well as for sex.

\section{Results}

\subsection{Patient baseline demographics characteristics}

The sample consisted of 386 patients who were on average 35.9 (STD $=11.8$ ) years old. Their mean duration of illness was 10.5 years $(\mathrm{STD}=10)$ and $64 \%$ of patients were male. $99 \%$ were Caucasian and Belgian natives. Their mean GAF score was 60.7 (STD =9.5). They had been admitted to the hospital on average 4.7 times (STD =4). $24.9 \%$ were outpatients at the time of assessment; $26.2 \%$ of the patients lived alone, $28.5 \%$ with their family, $14.8 \%$ with a partner, $12.5 \%$ in sheltered housing and $18.1 \%$ in residential facilities. The majority of the patients were unemployed (75.9\%).

The overall distribution of antipsychotic medication was as follows: $7.8 \%$ took amisulpride; $16.6 \%$ clozapine, $33.4 \%$ olanzapine, $16.1 \%$ quetiapine and $25.9 \%$ risperidone. On average they received $3(\mathrm{STD}=1.8)$ different concomitant treatments. Antipsychotics were combined with anticholinergics (11.7\%), antidepressants (40.7\%), benzodiazepines $(31.3 \%)$, mood stabilisers $(26.9 \%)$ and somatic medication $(28.8 \%) ; 1.0 \%$ of the patients were treated for diabetes, $1.6 \%$ of patients received a lipid lowering agent and $12.4 \%$ took antihypertensive medication. 
Table 1: Metabolic parameters per antipsychotic agent

\begin{tabular}{|c|c|c|c|c|c|c|}
\hline & $\begin{array}{l}\text { Amisulpride } \\
n=30(7.8 \%)\end{array}$ & $\begin{array}{l}\text { Clozapine } \\
n=65(16.6 \%) \\
\end{array}$ & $\begin{array}{l}\text { Olanzapine } \\
n=129(33.4 \%)\end{array}$ & $\begin{array}{l}\text { Queetiapine } \\
n=62(16.1 \%)\end{array}$ & $\begin{array}{l}\text { Risperidone } \\
n=100(25.9 \%) \\
\end{array}$ & $\mathbf{P}$ \\
\hline \multicolumn{7}{|c|}{ Clinical measures } \\
\hline Age (years) & $33.1 \pm 9.9$ & $35.9 \pm 9.8$ & $34.8 \pm 11.4$ & $38.8 \pm 13.4$ & $36.5 \pm 12.8$ & ns \\
\hline BMI $\left(\mathrm{kg} / \mathrm{m}^{2}\right)$ & $26.2 \pm 4.6$ & $27.7 \pm 5.1$ & $25.4 \pm 4.2$ & $26.6 \pm 6.3$ & $25.8 \pm 4.9$ & 0.0438 \\
\hline Waist $(\mathrm{cm})$ & $94.1 \pm 13.0$ & $99.0 \pm 14.4$ & $92.3 \pm 11.7$ & $93.6 \pm 18.1$ & $93.9 \pm 12.5$ & 0.0334 \\
\hline Mean dose (mg) & $720 \pm 305$ & $296 \pm 116$ & $16 \pm 7$ & $557 \pm 289$ & $5 \pm 5$ & NA \\
\hline \multicolumn{7}{|c|}{ Glucose levels (mg/dl) } \\
\hline $\begin{array}{l}\text { Fasting glucose } \\
(\mathrm{mg} / \mathrm{dl})\end{array}$ & $89.9 \pm 16.5$ & $92.9 \pm 19.8$ & $92.9 \pm 19.8$ & $90.3 \pm 12.8$ & $90.0 \pm 11.5$ & 0.0263 \\
\hline $\begin{array}{l}\text { Glucose } 2 \mathrm{~h} \\
(\mathrm{mg} / \mathrm{dl})\end{array}$ & $101.5 \pm 60.0$ & $95.9 \pm 47.5$ & $95.9 \pm 47.5$ & $102.1 \pm 48.9$ & $95.3 \pm 35.6$ & ns \\
\hline \multicolumn{7}{|c|}{ Insulin levels (mlU/L) } \\
\hline Fasting insulin & $10.1 \pm 5.8$ & $12.6 \pm 12.3$ & $11.3 \pm 9.4$ & $11.8 \pm 11.0$ & $9.34 \pm 6.8$ & ns \\
\hline Insulin $30 \mathrm{~min}$ & $81.3 \pm 48.4$ & $81.2 \pm 56.3$ & $78.3 \pm 46.6$ & $71.0 \pm 51.3$ & $71.4 \pm 52.3$ & ns \\
\hline Insulin $60 \mathrm{~min}$ & $69.8 \pm 58.6$ & $1074 \pm 95.2$ & $79.6 \pm 52.9$ & $77.2 \pm 59.4$ & $82.5 \pm 108.6$ & ns \\
\hline Insulin $120 \mathrm{~min}$ & $37.1 \pm 30.2$ & $44.0 \pm 56.9$ & $42.0 \pm 52.7$ & $41.3 \pm 47.7$ & $34.2 \pm 46.2$ & ns \\
\hline \multicolumn{7}{|l|}{ Insulin index } \\
\hline HOMA IR & $2.3 \pm 105$ & $3.2 \pm 3.6$ & $2.9 \pm 4.8$ & $2.8 \pm 2.9$ & $2.1 \pm 1.7$ & ns \\
\hline HOMA B\% & $146.2 \pm 78.09$ & $136.7 \pm 113.6$ & $148.3 \pm 90.6$ & $165.4 \pm 142.6$ & $144.8 \pm 159.6$ & ns \\
\hline \multicolumn{7}{|c|}{ Lipid levels (mg/dl) } \\
\hline Total cholesterol & $193.9 \pm 38.6$ & $195.2 \pm 34.6$ & $195.6 \pm 44.3$ & $193.7 \pm 38.0$ & $191.1 \pm 43.2$ & ns \\
\hline Triglycerides & $150.7 \pm 89.6$ & $172.7 \pm 78.5$ & $157.7 \pm 101.0$ & $144.8 \pm 79.1$ & $146.8 \pm 101.2$ & ns \\
\hline HDL cholesterol & $48.6 \pm 17.0$ & $46.1 \pm 13.4$ & $48.9 \pm 15.0$ & $55.2 \pm 14.4$ & $51.6 \pm 15.2$ & 0.0080 \\
\hline LDL cholesterol & $118.7 \pm 37.7$ & $114.3 \pm 31.2$ & $117.2 \pm 41.3$ & $111.4 \pm 35.9$ & $113.2 \pm 36.3$ & ns \\
\hline
\end{tabular}

(Values mean $\pm \mathrm{SD}, \mathrm{ANOVA})$.

\subsection{Metabolic risk factors and abnormalities}

Rates of metabolic and cardiovascular risk factors in this population were high: $65 \%$ were smoking, $21 \%$ had regular alcohol consumption, $28 \%$ had a family history of diabetes, $35.2 \%$ had a family history of dyslipidemia and $48.7 \%$ had a family history of cardiovascular disease.

The mean weight was $78.7 \mathrm{~kg}(\mathrm{STD}=16.0)$. The mean BMI was $26.1 \mathrm{~kg} / \mathrm{m}^{2}(\mathrm{STD}=5.0), 44.3 \%$ of the patients had a normal BMI, $37.1 \%$ were overweight and $18.7 \%$ were obese. The prevalence of the metabolic syndrome according to the adapted NCEP-ATP 111 was $29.3 \%$.

Furthermore, $5.7 \%(n=22)$ of patients met criteria for diabetes, another $16.3 \%(n=63)$ met criteria for prediabetes (1FG, 1GT or both). The mean fasting glucose level for the overall sample was $92.3 \mathrm{mg} / \mathrm{dl}$ (STD = 15.8 $\mathrm{mg} / \mathrm{dl})$ and differed significantly between antipsychotic treatments $(F(4,381)=2.79, p=0.0263)$ whereas no significant differences were observed with regard to glucose levels $2 \mathrm{~h}$ into the OGTT (Table 1).

The mean fasting insulin level was $11.0 \mathrm{mlU} / \mathrm{L}$, mean HOMA $\beta$ cell was $148 \%$ (HOMA $\beta$ cell $>100 \%$ in $63.7 \%$ of patients) and mean HOMA-IR was 2.7 (IR $>1$ in $83.7 \%$ of patients), indicative of $\beta$-cell overactivity to compensate for insulin resistance (Table 1). For none of these measures, significant influence of antipsychotic treatment was observed, although, all SGAs were associated with insulin resistance and increased $\beta$-cell function.

Mean fasting total cholesterol, triglycerides, and LDL cholesterol levels were similar across the antipsychotic treatments (Table 1.). Only HDL cholesterol differed significantly between antipsychotics $(F(4,381)=3.50$, $p=0.0080)$.

Mean fasting adiponectin levels were $8385 \mathrm{ng} / \mathrm{ml}(\mathrm{STD}=6016 \mathrm{ng} / \mathrm{ml})$; they were significantly lower in men $(7037 \mathrm{ng} / \mathrm{ml}(\mathrm{STD}=4965)$ than in women $(10538 \mathrm{ng} / \mathrm{ml}(\mathrm{STD}=6965))(p<0.0001, t=-5.26)$. 


\subsection{Adiponectin levels and metabolic outcomes}

Plasma adiponectin levels negatively correlated with waist $(r=-0.341, p<0.0001)$, triglycerides levels $(r=-0.298, p<0.0001)$, systolic blood pressure $(r=-0.119, p<0.0001)$ and fasting glucose levels $(r=-0.202, p<0.0001)$, whereas a positive correlation was observed with HDL levels $(r=0.404, p<0.0001)$. Plasma adiponectin levels were also negatively associated with $\operatorname{HOMA}-\mathrm{IR}(r=-0.202, p<0.0001)$.

Plasma adiponectin levels differed significantly as a function of BM1 category $(F(2,383)=20.56, p<0.0001)$. Patients with normal BM1 had significantly higher adiponectin levels than both overweight and obese patients $(p<0.05)$ (Table 2). There were no significant differences between overweight and obese patients. Plasma adiponectin levels were significantly lower in patients with metabolic syndrome, defined with adapted NCEPATP-III criteria compared to patients without metabolic syndrome $(p<0.0001, t=-6.61)$.

We observed significant differences of the rates of metabolic syndrome between the different antipsychotics $\left(X^{2}(4)=12.2, p<0.05\right)$, with the highest rate in patients taking clozapine $(46.1 \%)$, followed by $30.6 \%$ of patients on quetiapine, $27.0 \%$ of patients on risperidone, $26.7 \%$ of patients on amisulpride and $22.5 \%$ of patients on olanzapine.

Significant differences in mean adiponectin levels were observed as a function of the presence of glucose abnormalities $(F(2,383)=7.18, p<0.0001)$. Plasma adiponectin levels only significantly differed between diabetic and normogly-caemic patients $(p<0.05)$. No significant differences were observed between patients presenting a pre-diabetic status and patients with normal glycaemia nor between patients with a pre-diabetic status and those meeting criteria for diabetes. No significant differences were observed in the rates of type 11 diabetes between the different antipsychotics.

Mean adiponectin levels were significantly higher in patients with normal levels of triglycerides compared to those with abnormal levels $(\geq 150 \mathrm{mg} / \mathrm{dl})(p<.0001, t=-6.99)$. Mean adiponectin levels were significantly higher in patients with normal levels of HDL $(p<0.0001, t=-5.13)$ compared to those with low HDL levels (male $<40$ $\mathrm{mg} / \mathrm{dl}$, female $<50 \mathrm{mg} / \mathrm{dl})$.

Table 2: Plasma adiponectin as in function of metabolic abnormalities

\begin{tabular}{|c|c|c|c|}
\hline BMI & & & $* \mathbf{P}$ \\
\hline $\begin{array}{l}\begin{array}{l}\text { Normal } \\
(\boldsymbol{n}=\mathbf{1 7 1})\end{array} \\
10,378 \pm 7186 \\
\text { Glycaemia } \\
\text { status }\end{array}$ & $\begin{array}{l}\begin{array}{l}\text { Overweight } \\
(\boldsymbol{n}=143)\end{array} \\
7057 \pm 4420\end{array}$ & $\begin{array}{l}\begin{array}{l}\text { Obese } \\
(\boldsymbol{n}=72) \\
5967 \pm 3805\end{array}\end{array}$ & $<0.0001$ \\
\hline $\begin{array}{l}\text { Normal } \\
(\boldsymbol{n}=\mathbf{3 0 1}) \\
8825 \pm 6186\end{array}$ & $\begin{array}{l}\text { Prediabetes } \\
(\boldsymbol{n}=63) \\
7371 \pm 5526\end{array}$ & $\begin{array}{l}\text { Diabetes }(n=22) \\
4217 \pm 1631\end{array}$ & $<0.0001$ \\
\hline Elevated trig & lycerides (>150 n & lg/dl) & $* * \mathbf{P}$ \\
\hline $\begin{array}{l}\operatorname{No}(n=234) \\
9812 \pm 66226\end{array}$ & $\begin{array}{l}\text { Yes }(n=152) \\
6035 \pm 3977\end{array}$ & & $<0.0001$ \\
\hline $\begin{array}{l}\text { Low HDL ch } \\
<50 \text { mg/dl) }\end{array}$ & colesterol (male < & 40 mg/dl, female & $* * \mathbf{P}$ \\
\hline $\begin{array}{l}\text { No(n=263) } \\
9252 \pm 6404\end{array}$ & $\begin{array}{l}\text { Yes }(\boldsymbol{n}=123) \\
6345 \pm 4506\end{array}$ & & $<0.0001$ \\
\hline Metabolic sy & ndrome & & $* * \mathbf{P}$ \\
\hline $\begin{array}{l}\text { Adapted } \\
\text { NCEP-ATP } \\
(n=273) \\
9378 \pm 6367\end{array}$ & $\begin{array}{l}\text { III No } \\
\text { Adapted NCEP } \\
5779 \pm 4807\end{array}$ & $\begin{array}{l}\text {-ATPIII } \\
\text { Yes(n=113) }\end{array}$ & $<0.0001$ \\
\hline
\end{tabular}

(Values mean $\pm \mathrm{SD}$ in $\mathrm{ng} / \mathrm{ml} ;{ }^{*} \mathrm{ANOVA}, * * \mathrm{t}$-test). 


\subsection{Plasma adiponectin levels as a function of antipsychotic medication}

Significant overall differences in mean adiponectin levels were observed as a function of antipsychotic treatment $(F(4,381)=2.93, p=0.0209)$, although none of the pair-wise comparisons reached significance. When controlling for individual components of the metabolic syndrome and $\operatorname{sex}(F(4,374)=2.43, p=0.472)$, the effect of antipsychotic treatment remained significant, with the lowest mean levels in patients on clozapine and olanzapine (Table 3 ). Statistically significant differences $(p<0.05)$ in adiponectin levels were observed between olanzapine and risperidone, and olanzapine and amisulpride. No significant difference was observed between the other agents.

Table 3: Mean adiponectin levels (mean and std in $\mathrm{ng} / \mathrm{ml}$ ) per antipsychotic treatment

\begin{tabular}{ll}
\hline & Adiponectin level \\
\hline Amisulpride $(\boldsymbol{n}=\mathbf{3 0})$ & $9578 \pm 6682$ \\
Clozapine $(\boldsymbol{n}=\mathbf{6 5})$ & $7802 \pm 5083$ \\
Olanzapine $(\boldsymbol{n}=\mathbf{1 2 9})$ & $7091 \pm 5805$ \\
Quetiapine $(\boldsymbol{n}=\mathbf{6 2})$ & $9504 \pm 7292$ \\
Risperidone $(\boldsymbol{n}=\mathbf{1 0 0})$ & $9150 \pm 5515$ \\
\hline
\end{tabular}

\section{Discussion}

To our knowledge, this is the first study assessing adiponectin levels in a large sample of schizophrenic patients stable on antipsychotic monotherapy with a well evaluated metabolic status.

Fasting glucose levels were within normal ranges for the majority of the patients as opposed to insulin levels, HOMAIR and HOMA $\beta$ cell which were, on average elevated for the whole sample, indicating a trend for insulin resistance. These findings are in line with high rates of the metabolic syndrome in this sample.

Adiponectin levels in this population varied in the same way as described in the normal, overweight and obese general population (Arita et al., 1999), with associations between low adiponectin values and overweight and triglyceride levels. Also, adiponectin levels in schizophrenic patients with and without metabolic syndrome as well as with and without diabetes mirrored what is observed in the general population (Cote et al., 2005; Hotta et al., 2000; Matsuzawa et al., 2005a,b).

The most important finding of this study was that, after controlling for components of the metabolic syndrome and sex, the effect of antipsychotic treatment on adiponectin levels was significant. The lowest values were found in patients treated with olanzapine. Adiponectin levels in patients treated with clozapine were not significantly lower compared to the other atypicals, despite clozapine's known poor metabolic profile as reflected in the high rate of the metabolic syndrome in the current sample (46\%). The underlying mechanisms remain unclear. However, considering the unfavorable metabolic and vascular profile associated with low adiponectin levels, this may have important physical health implications (Cote et al., 2005; Guerre-Millo, 2008; Lihn et al., 2005).

Only a few and mainly small studies evaluated adiponectin levels in schizophrenia. Togo et al. $(n=33$, Togo et al., 2004) showed that patients undergoing treatment with olanzapine or risperidone had significantly higher adiponectin concentrations than age-matched healthy volunteers, even after controlling for BMI. Adiponectin concentrations decreased with increasing BMI in patients taking olanzapine, while elevated levels were observed in patients taking risperidone, regardless of adiposity. Cohn et al. $(n=9,2006)$ found insulin resistance and increased risk for type 2 diabetes in untreated schizophrenic patients, as well as a tendency for lower fasting adiponectin levels compared to matched healthy volunteers.. In a recent publication by Bai et al. (2007), found that independent of age and BMI, hypoadiponectinemia was associated with the majority of the measured metabolic parameters and was a predictive factor for metabolic syndrome in 188 clozapine-treated patients.

Three small, short-term prospective studies did not find evidence for significant changes in adiponectin levels after the initiation of an atypical antipsychotic. In a study of 13 patients started on olanzapine, Hosojima et al. $(n=13,2006)$ did not find a significant decrease in adiponectin levels after 4 weeks of treatment, which is in line with a 6-month prospective study in 7 patients who were also initiated on olanzapine (Murashita et al., 2005). A study in 24 patients with childhood-onset schizophrenia started on clozapine was unable to show significant 
changes in adiponectin levels over a 6 week period (Sporn et al., 2005).

The results of the present study may suggest a possible role of antipsychotic treatment in the variation of adiponectin levels in patients with schizophrenia, which is in agreement with the findings of Togo et al. (2004) where high BMI was associated with low adiponectin levels in olanzapine treated patients and with those of Bai et al. (2007) showing an association of adiponectin levels with metabolic parameters and metabolic syndrome as well as a study by Richards and colleagues who found that patients receiving olanzapine $(n=9)$ had significantly lower total serum adiponectin as compared with those on conventional treatment $(n=9)$ and 16 healthy sex-, BMI, and age-matched controls (Richards et al., 2006). Nevertheless, the results need to be interpreted with caution. Large prospective studies in patients recently switched/started on antipsychotic medication, preferably with long-term follow-up are needed to better establish a possible role of antipsychotics on adiponectin levels and other hormones influencing metabolic homeostasis.

The current study also has some limitations. First, it is a cross-sectional study and patients were not randomly assigned to treatment arms. Second, we failed to include other parameters, such as visceral fat assessment, dietary habits, physical activity level and other hormones which may play a role such as leptin, ghrelin, TNF- $\alpha$ and 1L-6 (Hug and Lodish, 2005; Jin et al., 2008; Meier and Gressner, 2004). Adiponectin together with a large number of other anorexic and oroxegenic factors plays a role in metabolic disturbance and CVD risk. Since we have only studied adiponectin levels, this limits the generalizability of our findings.

In conclusion, adiponectin levels in schizophrenic patients mirror what is observed in the general population, with the lowest levels in the most metabolically comprised subjects. Findings from the current study suggest that antipsychotic medication may also influence adiponectin regulation independently, a finding that should be confirmed in longitudinal studies with sufficiently large samples.

\section{Role of Funding Source}

The study was funded by an unrestricted grant from Bristol-Myers Squibb.

\section{Contributors}

Study design: L Hanssens, M De Hert, R van Winkel

Data collection: M De Hert, D Van Eyck

Laboratory analysis: J Collette

Statistics: M Wampers

Writing manuscript: L Hanssens and M De Hert wrote the first draft of the manuscript R van Winkel, M Wampers, D Van Eyck, A Scheen, JY Reginster, J Collette and J Peuskens commented on this first draft and contributed to the subsequent revision.

\section{Conflict of Interest}

L Hanssens was an employee of BMS at the time of the study, study is part op PhD curriculum in Public Health and epidemiology at the University of Liège.

$\mathrm{R}$ van Winkel has been a consultant for Eli Lilly Lilly and has received honoraria from Eli Lilly and JanssenCilag.

M Wampers has no conflicts of interest to disclose relative to the article.

D Van Eyck has received speakers fees from Bristol-Myers Squibb and Sanofi-Aventis.

A Scheen has been a consultant for Sanofi-Aventis, AstraZeneca, GlaxoS-mithKline, and has received speaker fees from Sanofi-Aventis.

J Colette has no conflicts of interest to disclose relative to the article.

JY Reginster has no conflicts of interest to disclose relative to the article.

J Peuskens has been a consultant for, received grant/research support and honoraria from, and been on the speakers/advisory boards of AstraZeneca, Lundbecl, Janssen-Cilag, Eli Lilly, Pfizer, Sanofi and Bristol-Myers Squibb.

M De Hert has been a consultant for, received grant/research support and honoraria from, and been on the speakers/advisory boards of AstraZeneca, Lundbeck, Janssen-Cilag, Eli Lilly, Pfizer, Sanofi-aventis and BristolMyers Squibb. 


\section{Acknowledgements}

We want to thank the nurses from the somatic department of the University Psychiatric Centre and laboratory technicians from the Department of Clinical Biology of Liège for their help with the handling and the analysis of the samples.

\section{References}

Allison, D.B., Casey, D.E., 2001. Antipsychotic-induced weight gain: a review of the literature. Journal of Clinical Psychiatry 62 (Suppl 7), $22-31$

Allison, D.B, Fontaine, K.R., Heo, M, Mentore, J.L., Cappelleri, J.C, Chandler, LP., Weiden, P.J., Cheskin, L.J, 1999. The distribution of body mass index among individuals with and without schizophrenia. Journal of Clinical Psychiatry 60 (4), $215-220$.

Ader, M., Kim, S.P., Catalano, K.J., Ionut, V., Hucking, K., Richey, J.M., Kabir, M., Bregman, N., 2005. Metabolic dysregulation with atypical antipsychotics occurs in the absence of underlying disease: a placebo-controlled study of olanzapine and risperidone in dogs. Diabetes 54, 862-871.

Arner, P., 2001. Free fatty acids-do they play a central role in type 2 diabetes? Diabetes, Obesity and Metabolism 3 (Suppl 1), S11-S19.

Arita, Y., Kihara, S., Ouchi, N., Takahashi, M., Maeda, K., Miyagawa, J., Hotta, K., Shimomura, I., Nakamura, T., Miyaoka, K., Kuriyama, H., Nishida, M., Yamashita, S., Okubo, K., Matsubara, K., Muraguchi, M., Ohmoto, Y., Funahashi, T., Matsuzawa, Y, 1999. Paradoxical decrease of an adipose-specific protein, adiponectin, in obesity. Biochemical and Biophysical Research Communication 257, 79-83.

Bai, Y.M., Chen, J.Y, Yang, W.S., Chi, Y.C., Liou, Y.J., Lin, C.C., Wang, Y.C, Su, T.P., Chou, P., 2007. Adiponectin as a potential biomarker for the metabolic syndrome in Chinese patients taking clozapine for schizophrenia. Journal of Clinical Psychiatry 68,1834-1839.

B-Bridge International, Inc. Human Adiponectin ELISA kit User Manual, 2002.

Berg, A.H., Combs, T.P., Du, X., Brownlee, M., Scherer, RE., 2001. The adipocyte-secreted protein Acrp30 enhances hepatic insulin action Nature Medicine 7, 947-953.

Berg, A.H., Combs, T.E., Scherer, P.E., 2002. ACRP/adiponectin: an adipol<ine regulating glucose and lipid metabolism. Trends in endocrinology and metabolism 13 (2), 84-89.

Bergman, RN., Ader, M., 2005. Atypical antipsychotics and glucose homeostasis. Journal of Clinical Psychiatry 66, $504-514$.

Casey, D.E., 2005. Metabolic issues and cardiovascular disease in patients with psychiatric disorders. American Journal of Medicine, 118 (Suppl 2), 15-22.

Cohn, TA., Remington, G., Zipurski, RB., Azad, A, Connolly, P., Wolever, T, 2006. Insulin resistance and adiponectin levels in drug-free patients with schizophrenia: a preliminary report Canadian Journal of Psychiatry 51 (6), 382-386.

Cote, M., Mauriege, P., Bergeron, J., Alméras, M., Tremblay, A., Lemieux, I., Després, J.P., 2005. Adiponectinemia in visceral obesity: impact on glucose tolerance and plasma lipoprotein and lipid levels in men. Journal of Clinical Endocrinology and Metabolism 90 (3), $1434-$ 1439.

De Hert, M., van Winkel, R, Van Eyck, D., Hanssens, L, Wampers, M., Scheen, A., Peuskens, J., 2006a. Prevalence of the metabolic syndrome in patients with schizophrenia treated with antipsychotic medication. Schizophrenia Research 83 (1), 87-93.

De Hert, M., van Winkel, R, Van Eyck, D., Hanssens, L, Wampers, M., Scheen, A., Peuskens, J., 2006b. Prevalence of diabetes, metabolic syndrome and metabolic abnormalities in schizophrenia over the course of the illness: a cross-sectional study. Clinical Practice and Epidemiology in Mental Health 2 (14). doi:10.1186/1745-0179-2-14.

De Nayer, A, De Hert, M., Scheen, A, Van Gaal, L, Peuskens, J., 2005. Conference report: Belgian consensus on metabolic problems associated with second-generation antipsychotics. International Journal of Psychiatry and Clinical Practice 9 (2), $130-137$.

Dekker, J., Funahashi, T, Nijpels, G., Pilz, S., Stehouwer, C, Snijder, M., Bouter, L, Matsuawa, Y, Shimomura, I., Heine, R, 2008. Prognostic value of adiponectin for cardiovascular disease and mortality. Journal of Clinical Endocrinology and Metabolism 93 (4), 14891496.

Dufresne, R, 2007. Weighing in: emergent diabetes mellitus and second-generation antipsychotics. The annals of Pharmacotherapy 41,17251370.

Elman, I., Goldstein, D.S., Eisenhofer, G., Folio, J., Malhotra, A.K., Adler, CM., Pickar, D., Breier, A., 1999. A mechanism of peripheral noradrenergic stimulation by clozapine. Neuropsychopharmacology 1 (20), 29-34. 
Elman, I., Goldstein, D.S., Green, AL, Eisenhofer, G., Folio, J., Holmes, C.S., Pickar, D., Breier, A., 2002. Effects of risperidone on the peripheral noradrenegic system in patients with schizophrenia: a comparison with clozapine and placebo. Neuropsychopharmacology 27 (2), 293-300.

Elmquist, J., Flier, E, 2004. The fat-brain axis enters a new dimension. Science 304, 63-64.

Expert Committee on the Diagnosis and Classification of Diabetes Mellitus, 2003. Follow-up report on the diagnosis of diabetes mellitus. Diabetes Care 26, 3160-3166.

Expert Committee on the Diagnosis and Classification of Diabetes Mellitus, 2008. Position statement on the diagnosis and classification of diabetes mellitus. Diabetes Care 31 (Suppl 1), S55-S60.

Expert Panel on Detection and Evaluation of Treatment of High Blood Cholesterol in Adults, 2001. Executive summary of the third report of the National Cholesterol Education Program (NCEP) expert panel on detection, evaluation and treatment of high blood cholesterol in adults (Adult Treatment Panel III). JAMA 285, 2486-2497.

Grundy, S.M., Cleeman, J.I., Merz, C.N., Brewer, H.B., Clark, L.T., Hunninghake, D.B., Pasternak, R.C., Smith, S.C., Stone, N.J., For the Coordinating Committee of the National Cholesterol Education Program, Endorsed by the National Heart, Lung, and Blood Institute, American College of Cardiology Foundation, and American Heart Association, 2004. Implications of recent clinical trials for the National Cholesterol Education Program Adult Treatment Panel III guidelines. Circulation 110 (2), 227-239.

Guerre-Millo, M., 2008. Adiponectin: an update. Diabetes and Metabolism 34, 12-18.

Haupt, D.W., Newcomer, J.W, 2001. Hyperglycemia and antipsychotic medications. Journal of Clinical Psychiatry 62 (27), 15-26.

Hara, K., Yamauchi, T, Kadowaki, T, 2005. Adiponectin: an adipol<ine linking adipocytes and type 2 diabetes in humans. Current Diabetes Reports 5 (2), 136-140.

Hennekens, C, Hennekens, AC, Hollar, D., Casey, D.E., 2005. Schizophrenia and increased risks of cardiovascular disease. American Heart Journal 150 (6), 1115-1121.

Homel, P., Casey, D., Allison, D.B., 2002. Changes in body mass index for individuals with and without schizophrenia, $1987-1996$. Schizophrenia Research 55 (3), 277-284.

Hosojima, H., Togo, T, Odawara, T, Hasegawa, K., Miura, S., Kato, Y, Kase, A., Uchikado, H., Hirayasu, Y, 2006. Early effects of olanzapine on serum levels of ghrelin, adiponectin and leptin in patients with schizophrenia? Journal of Psychopharmacology 20, 75-79.

Hotta, K., Funahashi, T, Arita, Y, Takahashi, M., Matsuda, M., Okamoto, Y, Iwahashi, H., Kuriyama, H., Ouchi, N., Maeda, K., Nishida, M., Kihara, S., Sakai, N., Nakajima, T, Hasegawa, K., Muraguchi, M., Ohmoto, Y, Nakamura, T, Yamashita, S., Hanafusa, T, Matsuzawa, Y, 2000. Plasma concentrations of a novel, adipose-specific protein, adiponectin, in type 2 diabetic patients. Arteriosclerosis, Thrombosis, and Vascular Biology 20, 1595-1599.

Hug, C, Lodish, H.F., 2005. The role of the adipocyte hormone adiponectin in cardiovascular disease. Current Opinion in Pharmacology 5 (2), 129-134

Jin, H., Meyer, J.M., Jeste, D.V., 2002. Phenomenology of and risk factors for new-onset diabetes mellitus and diabetic ketoacidosis associated with atypical antipsychotics: an analysis of 45 published cases. Annals of Clinical Psychiatry 14 (1), 59-64.

Jin, H., Meyer, J.M., Jeste, D.V., 2004. Atypical antipsychotics and glucose dysregulation: a systematic review. Schizophrenia Research 71 $(2-3), 195-212$

Jin, H., Meyer, J.M., Mudaliar, S., Jeste, D.V., 2008. Impact of atypical antipsychotic therapy on leptin, ghrelin, and adiponectin. Schizoprenia Research 100 (1-3), 70-85.

Kroeze, W.K., Hufeisen, S.J., Popadak, B.A., Renock, S.M., Steinberg, S., Ernsberger, P., Jayathilake, K., Meltzer, H.Y., Roth, B.L, 2003 H1 -histamine receptor affinity predicts short-term weight gain for typical and atypical antipsychotic drugs. Neuropsychopharmacology 28 , 519-526.

Lihn, A.S., Pedersen, S.B., Richelsen, B., 2005. Adiponectin: action, regulation and association to insulin sensitivity. Obesity Reviews 6,1321.

Matthews, D.R., Hosker, J.P., Rudenski, A.S., Naylor, B.A., Treacher, D.F., Turner, R.C., 1985. Homeostasis model assessment: insulin resistance and beta-cell function from fasting plasma glucose and insulin concentrations in man. Diabetologia 28,412-419.

Matsubara, M., Maruako, S., Katayose, S., 2002. Decreased plasma adiponec-tin concentrations in women with dyslipidemia. The journal of clinical endocrinology \& metabolism 87 (6), 2764-2769. 
Matsuda, M., Shimomura, I., Sata, M., Arita, Y., Nishida, M., Maeda, N., Kumada, M., Okamoto, Y., Nagaretani, H., Nishizawa, H., Kishida, K., Komuro, R., Ouchi, N., Kihara, S., Nagai, R., Funahashi, T., Matsuzawa, Y., 2002. Role of adiponectin in preventing vascular stenosis. The Journal of Biological Chemistry 277 (40), 37487-37491.

Matsuzawa, Y., Funahashi, T., Kihara, S., Shimomura, I., 2004. Adiponectin and metabolic syndrome. Arteriosclerosis, Thrombosis and Vascular Biology 24(1), 29-33.

Matsuzawa, Y, 2005a. Adipocitokines and metabolic syndrome. Seminars in Vascular Medicine 5, 34-39.

Matsuzawa, Y, 2005b. Adiponectin: identification, physiology and clinical relevance in metabolic and vascular disease. Atherosclerosis Supplements 6, 7-14.

Meier, U, Gressner, A., 2004. Endocrine regulation of energy metabolism: review of pathobiochemical and clinical chemical aspects of leptin, ghrelin, adiponectin and resistin. Clinical Chemistry 50 (9), 1511-1525.

Meyer, J.M., Koro, CE., 2004. The effects of antipsychotic therapy on serum lipids: a comprehensive review. Schizophrenia Research 70 (1), $1-17$

Murashita, M., Kusumi, I., Inoue, T, Takahashi, Y, Hosoda, H., Kangawa, K., Koyama, T, 2005. Olanzapine increases plasma ghrelin level in patients with schizophrenia. Psychoneuroendocrinology 30,106-110.

Newcomer, J.W., 2005. Second-generation (atypical) antipsychotics and metabolic effects: a comprehensive literature review. CNS Drugs 19 (Suppl 1), 1-93.

Newcomer, J.W., 2007a. Metabolic considerations in the use of antipsychotic medications: a review of recent evidence. Journal of Clinical Psychiatry 68 (suppl 1), 20-27.

Newcomer, J.W., 2007b. Metabolic syndrome and mental illness. American Journal of Managed Care 13 (Suppl 7), $170-177$

Reynolds, G.R, Zhang, Z.J., Zhang, X.B., 2002. Association of antipsychotic drug-induced weight gain with 5-HT2C receptor gene polymorphism. Lancet 359 (9323), 2086-2087.

Richards, A.A., Hickman, I.J., Wang, AY, Jones, A.L., Newell, E, Mowry, B.J., Whitehead, J.R, Prins, J.B., Macdonald, G.A., 2006 Olanzapine treatment is associated with reduced high molecular weight adiponectin in serum: a potential mechanism for olanzapine-induced insulin resistance in patients with schizophrenia. Journal of Clinical Psychopharmacology 26 (3), 232-237.

Sato, C, Yasukawa, Z., Honda, N., Matsuda, T., Kitajima, K., 2001. Identification and adipocyte differentiation-dependent expression of the unique disialic acid residue in an adipose tissue-specific glycoprotein, adipo Q, Journal of Biological Chemistry 276 (31), $28849-28856$.

Scheen, A.J., De Hert, M., 2005. Drug-induced diabetes mellitus: the example of atypical antipsychotics. Revue Médicale de Liege 60 (5-6), $455-460$.

Scheen, AJ., De Hert, M., 2007. Abnormal glucose metabolism in patients treated with antipsychotics. Diabetes \& Metabolism 33 (3), $169-$ 175 .

Sherer, RE., Wiliams, S., Fogliano, M., Baldini, G., Lodish, H.F., 1995. A novel serum protein similar to CI q, produced exclusively in adipocytes. Journal of Biological Chemistry 270,26746-26749.

Sporn, A.L, Bobb, AJ., Gogtay, N., Stevens, H., Greenstein, D.K, Clasen, LS, Tossell, J.W., Nugent, T, Gochman, PA, Sharp, W.S., Mattai, A, Lenane, M.C, Yanovski, JA, Rapoport, J.L., 2005. Hormonal correlates of clozapine-induced weight gain in psychotic children: an exploratory study. Journal of the American Academy of Child and Adolescent Psychiatry 44 (9), 925-933.

Togo, T., Kojima, K., Shoji, M., Kase, A., Uchikado, H., Katsuse, O., Iseki, E., Kosaka, K., 2004. Serum adiponectin concentrations during treatment with olanzapine or risperidone: a pilot study. International Clinical Psychopharmacology 19, 37-40.

Tschoner, A., Engl, J., Laimer, M., Kaser, S., Rettenbacher, M, Fleischhacker, W.W., Patsch, J.R, Ebenbichler, CF., 2007. Metabolic side effects of antipsychotic medication. International Journal of Clinical Practice 61 (8), 1356-1370.

Van Winkel, R., de Hert, M., Van Eyck, D., Hanssens, L, Wampers, M., Scheen, A, Peuskens, J., 2006. Screening for diabetes and other metabolic abnormalities in patients with schizophrenia and schizoaffective disorder: evaluation of incidence and screening methods. Journal of Clinical Psychiatry, 67 (10), 1493-1500.

Van Winkel, R, De Hert, M., Wampers, M., Van Eyck, D., Hanssens, L, Scheen, A, Peuskens, J., 2008. Major changes in glucose metabolism including new-onset diabetes within 3 months after initiation or switch of atypical antipsychotic medication in patients with schizophrenia and schizoaffective disorder. Journal of Clinical Psychiatry 69,472-479.

Weyer, C, Funahashi, T., Tanaka, S., Hotta, K., Matsuzawa, Y, Pratley, RE., Tataranni, P.A., 2001. Hypoadiponectomia in obesity and type 2 diabetes: close association with insulinresistance and hyperinsulinemia. Journal of Clinical Endocrinology and Metabolism 86,1930-1935. 
Published in: Schizophrenia Research (2008), vol.106, iss.2-3, pp.308-314

Status: Postprint (Author's version)

Wu, M.K., Huang, C.Y, Liou, Y.J., Wang, C.K., Lee, S.D., 2007. Glucose-insulin homeostasis, lipid profiles and GH-IGF-IGFBP axis in clozapine-treated schizophrenic obesity versus non-psychiatric obesity. International Journal of Obesity advance online publication. doi:10.1038/sj.ijo.0803750

Yamauchi, T, Kamon, J., Waki, H., Terauchi, Y, Kubota, N., Hara, K., Mori, Y, Ide, T., Murakami, K., Tsuboyama-Kasaoka, N., Ezaki, O., Akanuma, Y, Gavrilova, O., Vinson, C, Reitman, M.L, Kagechika, H., shudo, K., Yoda, M., Nakano, Y, Tobe, K., Nagai, R, Kimura, S., Tomita, M., Froguel, P., Kadowaki, T, 2001. The fat-derived hormone adiponectin reverses insulin resistance associated with both lipoatrophy and obesity. Nature Medicine 7, 941-946. 